\title{
Moving to The Beats: The Effect of Dance Education on Early Self-Regulation
}

\author{
Elindra Yetti ${ }^{1}$ \\ Universitas Negeri Jakarta, Indonesia ${ }^{l}$
}

DOI: https://doi.org/10.21009/JPUD.152.11

Received: September $15^{\text {th } 2021 . A c c e p t e d: ~ O c t o b e r ~} 4^{\text {th }} 2021$. Published: November $30^{\text {th }}, 2021$

\begin{abstract}
Self-regulation in children is an important thing that needs to be prepared from an early age. Besides affecting children's school readiness, this also makes it easier for children to have good academic achievements. This study aims to determine the influence of moving to the beat of early childhood self-regulation. This research was conducted on kindergarten group B students in East Jakarta. The research method used is a quasi-experiment method with a sample of 20 students. The data collection technique uses observations by analysing paired t-test statistical data. The results of the study explained that there was a significant effect of moving to the beat of early childhood selfregulation. The significance level is $0.000<0.05$, which means that $\mathrm{H} 0$ is rejected and $\mathrm{H} 1$ is accepted, this indicates a significant difference between the pre-test and post-test. For further research, it is recommended to look at the influence of other factors on early childhood self-regulation.
\end{abstract}

Keywords: Dance Education, Early childhood, Self-Regulation

\footnotetext{
${ }^{1}$ Corresponding Author:

Early Childhood Education Postgraduate Program

Universitas Negeri Jakarta

Email: elindrayetti@unj.ac.id
} 


\section{INTRODUCTION}

Recent research has demonstrated the importance of working on self-regulation. Young children in early childhood services as a way to escape widening disparities in learning and achievement when children begin school, especially for disadvantaged children (Diamond, 2016). The child's capacity to self-regulate is recognized as a major indicator of important life outcomes, including academic achievement, social and emotional wellbeing, and physical and financial performance (Duckworth et al., 2012). It also plays an important role in the transition and success of children in the school environment (Blair \& Raver, 2015).

Highlighting pre-school years as a crucial stage for learning psychological, linguistic and cognitive skills (Gammage, 2019). Today many children attend preschool in many countries (OCDE, 2013). However, many children, especially from disadvantaged social backgrounds, start schools that lack critical skills for a successful transition to school, namely self-regulation (Blair \& Razza, 2007). Process quality refers to experiences of the child and includes the psychological mental, physical, and educational facets of children's activities and relationships with teachers, peers, and materials, that are seen as proximal determinants of child development (Howes et al., 2008; Pianta et al., 2005; Thomason \& La Paro, 2009)

The gap in early self-regulation skills among children is at risk in school failure and their peers who have better self-regulation are increasing over time, this occurs for various reasons (Jacobson-Chernoff, J., Flanagan, K. D., McPhee, C., \& Park, 2007). The process of developing early self-regulation that differs significantly among children is an important component of school readiness. Therefore, in his research, Williford et al., (2013) arguing the importance of expanding the understanding of the factors that explain differences in children's self-regulation to design effective interventions will help close the gap in school readiness. Children describe school needs to regulate their emotional, cognitive, and behavioural responses. The child characterizes the school as a dynamic environment, placing emphasis on the challenges of outside environmental regulations. Children describe the difficulties associated with navigating complex social interactions, often without assistance from adult support. Adults need to inform strategies to support the emerging self-regulation abilities of children (Booth et al., 2019).

According to a study conducted by Cadima et al. (2016), explaining that children show greater improvement in self-regulation when teachers and children experience a closer relationship. This research presents one of the first pieces of evidence that the relationship between teacher and child and the classroom environment is critical for the development of self-regulation. Laws that develop into self-regulation tend to play a crucial role in certain cognitive and socio-emotional outcomes as children grasp contextual selfregulation, and this is a valuable effort for the future. This discovery has implications for the understanding of the role of class social mechanisms in the production of selfregulation. 
Social, emotional, and cognitive functions are very intertwined throughout the lifespan. Children 2-3 years of age with a higher degree of casual parent-child music interaction in the home had reduced auditory distractibility assessed at the same time (Putkinen et al., 2013) and increased parental attention control abilities recorded at 4-5 years (Williams et al., 2015a). These higher levels of focus could transform into continued attention to teaching directions and increased persistence in early childhood education. The capacity to control attention and emotions is a form of self-regulation that provides a basis for school readiness by fostering provisions that promote learning and sustain positive social ties (Blair \& Raver, 2015). Whereas the opinion Flook et al., (2010) of the importance of developing such competencies early in life is underlined by studies that show that self-regulation in childhood predicts health, financial stability, and educational attainment into adulthood.

Eunhye et al., (2015) revealed that the results of her research demanded more professional development programs that focused on teacher beliefs and attitudes towards children. To apply a new module of instructional behaviour, research has shown that teachers may need to reflect and change their existing beliefs, values, and attitudes towards children because this affects indirectly on children's self-regulation. Selfregulation can be influenced by several variables, such as moving according to the rhythm can affect self-regulation, because when the child moves in accordance with the rhythm of the music, there is an effort in regulating body movements in accordance with the rhythm of the music. In line with the research conducted by Schibli et al., (2015) it was explained that early childhood children received music instruction and did significantly better on self-regulation tasks. By using Potential related events (ERP) to determine the relationship between music, self-regulation, and brain response. The findings show finding a significant increase in the amplitude of the initial ERP component (50-200 Ms) for musician children compared to non-musician children, in addition to lower reaction times and improved output accuracy. Children who were enrolled in the music community did much better than children who were not registered to respond to the go note at a higher frequency $(2000 \mathrm{~Hz})$, an outcome that was also attributed to variations in ERP between the two classes. The final findings of this research affirm the association between the practice of self-regulation skills by music and the level of executive functioning of children (i.e., inhibitory control and selective attention). Implications for music training interventions and implementation of music training in the school environment, especially as applied to children who are poor. Dance stimulation by listening to music, and children perform dance movements in accordance with the rhythm of music, which is done continuously can train children to improve their self-regulation skills.

Music is a very important element of moving activities for children. Music with a beat of rhythm accompanies most moving activities such as dancing or gymnastics. Research by Williams and Berthelsen (2019), identified Early stress experiences in disadvantaged households can affect children's brain architecture, often manifesting in poor selfregulation functions. Children from less advantaged backgrounds are more likely to have poorer self-regulation abilities, often due to adverse home conditions and resulting in 
stress-related physiological reactions (Blair \& Raver, 2012, 2015). While there are documented benefits from coordinated movement activities to improve self-regulation, some interventions have focused exclusively on music and rhythmic activities. The findings indicate that rhythm and movement interventions have the potential to support the development of self-regulation skills in preschool. Early childhood music education is another field that is full of claims regarding the benefits of early musical experience, but the light on empirical evidence that the combined and individual effects of music and dance on the regulation of children's behaviour and children's social competence are of course topics that interesting and important for future research (Lobo \& Winsler, 2006).

Beats are fundamental references to production and perceptions of rhythm. The experience of perceptions of the musical rhythm depends on the interaction between the sounding rhythmic event and the induced reference structure and is used by listeners to understand sound. Research on spontaneous music movements induced by music shows that the music metric structure layer is associated with periodic movement patterns. The aim of this study was to investigate changes in listener's gestures in relation to changes in the micro rhythmic design of the basic pulse in 'Left \& Right' songs by D'Angelo. The theory of responses to changes in the beat micro-rhythmic design from parts 1 to part 2 of the tone, uses the previous analytical work previously on micro-rhythmic relations in tone and the theory of dynamics present at the beginning of research. The result is showing a movement that aims to examine the listener's changes in gestures (Danielsen et al., 2015).

Based on some relevant research that has been described, many self-regulation studies focus on the relationship between teachers and students, as well as the relationship between students and parents, but not many studies have seen the effects of moving in accordance with the music's rhythm in children's self-regulation. At the initial observation of kindergarten students, many children have low self-regulation ability, can be seen the ability to control themselves, make their own decisions, take responsibility for actions, control themselves in carrying out various activities such as learning and playing. But on the other hand, there are some children who have good self-regulation because of the close relationship between teacher and child.

\section{THEORITICAL STUDY}

\subsection{Moving to the Beats in Dance Education}

The basic skills needed for singing and moving appear in the first year of a child's life (Fujii \& Schlaug, 2013). The ability to sing and move according to the rhythm of a rhythmic auditory stimulus appears from the beginning of a child's development and involves perceptual, motoric, and sensorimotor processes. The similarity between singing and the suitability of motion with the beat of rhythm may be rooted in human biological factors (Dalla Bella et al., 2015). Moving to the rhythm of music can improve the perception of time, providing an interesting explanation of why we often move when listening to music. Moving to the beat is like doing a dance. However, dance education is 
unique because it plays three areas of intellectual activity namely physical, emotional and equality of emphasis and unity of impulses. This emotional aspect is very important in many areas of the curriculum, in moving activities with music, the intellectual aspects of activities are there, functioning as a link between feelings and actions themselves.

The use of music to help children learn and develop has a relatively long history (Hallam, 2010). Music can help increase the effects of dichotic, which can improve children's short-term memory, reduce distractibility, and discuss information. Listening to music has also been found to improve performance in selective tasks. In addition, similar results have been found in resolving them with improvements in social functioning, feelings of well-being and self-expression. In children, early morning, musical and ritual games related to children and adults, support, and language and cognitive development (Charissi \& Rinta, 2014).

Early childhood fondness for the rhythm of the music, allows teachers and parents to involve the rhythm of music in all activities that develop various potential children. One proven approach to affect neuronal performance is through formal music instruction and casual musical interactions with an increasingly growing body of studies illustrating the cognitive effects of these practices (George \& Coch, 2011; Putkinen et al., 2015). This refers to research using the most advanced technology to study the brain, in addition to psychological studies and quantitative and qualitative education. This explains how music skills could move to other activities if the processes involved are similar. It explores evidence relating to the impact of music skills on language development, literacy, numeracy, measures of intelligence, general achievement, creativity, fine motor coordination, concentration, self-confidence, emotional sensitivity, social skills, teamwork, self-regulation, and relaxation. This shows that the positive effects of involvement with music on personal and social development only occur if it is a pleasant and rewarding experience. This has implications for the quality of teaching.

Likewise, the relation between music rhythm and the development of self-regulation in children has been investigated by Zachariou and Whitebread (2016) namely pioneering efforts to unite the idea of playing music and self-regulation and reporting a study aimed at exploring the self-regulation of 6-year-old children while playing music. Observations were made on ten children aged 6 years when they were involved in music playing sessions. The results show that music games allow self-regulation behaviour to emerge. An understanding of the relationship between playing music and self-regulation can inform not only the theoretical foundations that show the relationship between activities with the rhythm of music and self-regulation but also current teaching practices in relation to music education. Supported by Varela and Abrami (2014) which reviews available empirical evidence to identify the relationship between the processes contained in the independent regulation model and (Zimmerman, 2010) music learning variable. The discussion proposes that future research can benefit from investigating self-regulation in a broader spectrum of musicians and exploring exploratory understandings driven by participants about self-regulation theory. 


\subsection{Self-Regulation}

Broad self-regulation refers to the ability of children to intentionally modulate thoughts, emotions, and behaviour in response to certain situations (McClelland \& Cameron, 2012). Recent evidence shows that, in early childhood, self-regulation is best described as an integrative unity construct (Wiebe et al., 2008). The critical dimension of early learning competence in the years before the school is self-regulation. Self-regulation allows individuals to manage their emotions and direct their attention, thoughts, and actions to meet adaptive goals.

These skills increase children's readiness to learn. Self-regulation developed rapidly in the early years and was an important predictor of educational and life success. Early selfregulation skills are important in the successful transition to the formal school environment, and higher predict the initial primary academic achievement than the general measure of intelligence (Williams et al., 2015b). In line with this view, Ponitz et al., (2009) in his research, he focused on the integrative nature of self-regulation and used direct measures to identify interrelated skills, including skills to focus, remember instruction (working memory), and stop inappropriate behaviour (inhibition control). The third combination of these skills is very important in the success of class arrangements because they tend to be influenced by the interaction process in the classroom.

In the statement of Salisch et al., (2015) examined children's self-regulation, children's self-regulation contributed to their predictions of emotional knowledge in samples in German kindergartens. Age differences show that among 5-year-olds, the influence of self-regulation of children's behaviour on their knowledge of emotions is more integrated with their language skills and self-regulation. Because Long research shows that both self-regulation and emotional knowledge are predictors of academic success in kindergarten and the first years of schooling. It is necessary for children to be able to organize themselves to increase their knowledge and it is also important for them to realize when to organize themselves by their emotional knowledge. If emotional knowledge helps children to maintain non-disruptive relationships with teachers and peers, this can be an alternative to academic success. Research Blair and Raver (2015) shows that self-regulation can be a key development factor that helps children achieve the same positive results even if they come from different backgrounds. Taken together, this study shows that self-regulation shows multifocality, depending on people and contextual factors.

Factors that can improve self-regulation in children is one of them is the musical ability that is brought by a human child from birth. Zachariou and Whitebread (2016) learning to play music from an ethnomusicological perspective, when explaining the modes of activity that occur during playing music, can often develop self-regulating behaviour on. All these behaviours show that children adopt self-regulation strategies and that they also monitor, control, and evaluate their progress. Nonetheless, research explicitly studying relationships playing music and self-regulation is quite rare. 


\section{METHOD}

The research method used a quasi-experimental which was carried out on kindergarten students group B in East Jakarta. Quasi-experimental studies were chosen because they do not require a correct control group but can include a comparison group (Marsden \& Torgerson, 2012). Self-regulation can be better because of several factors that influence it, such as the effect of moving to the rhythm. If the child's self-regulation is good, it can help better school readiness. The purpose of this study is to prove previous research in the effect of movement on the beats of self-regulation of early childhood.

\subsection{Sample and Data Collection}

The number of respondents consisted of 20 kindergarten students. The technique of collecting data through observation using field notes instruments used by the teacher. The research instrument was a non-test consisting of observation items made by the teacher to find early-childhood self-regulation. This method was chosen to see and prove previous research on the effect of rhythmic movement on children's self-regulation.

\subsection{Analysing of Data}

Data analysis using paired t-test, which is to test differences in pre-test and post-test. Using the SPSS program to identify the results of paired t tests samples.

\section{RESULT AND DISCUSSION}

\subsection{Result}

Implementation of moving to the beat activities of music through various forms of motion. Students carry out Activities move to the rhythm for 8 weeks. Moving activities with the rhythm of music is done by using several types of slow, medium, and fast tempo. Movement activities follow the same rhythm as dancing, by doing movements based on the stimulation of musical accompaniment in accordance with the theme. Initially the children do the process of exploration and improvisation of motion. Then the motion of exploration results is repeated using the rhythm of music. The activity of moving to the rhythm of the music is done repeatedly, so the child can feel the motion in accordance with the rhythm and having fun. After the implementation of the activity moves to the music rhythm, followed by a post-treatment test (final test) to see changes in selfregulation of early childhood (see table 1).

Table 1. Early Self-Regulation of Pre-Test and Post-Test (N=20)

\begin{tabular}{cccc}
\hline No & Students & Pre-Test & Post-Test \\
\hline $\mathbf{1}$ & AN & 23 & 27 \\
$\mathbf{2}$ & AC & 25 & 30 \\
$\mathbf{3}$ & AB & 28 & 34 \\
$\mathbf{4}$ & AR & 28 & 35 \\
$\mathbf{5}$ & ADL & 30 & 35 \\
$\mathbf{6}$ & BC & 31 & 36 \\
$\mathbf{7}$ & BD & 26 & 36
\end{tabular}

http://journal.unj.ac.id/unj/index.php/jpud 401 


\begin{tabular}{cccc}
$\mathbf{8}$ & BG & 26 & 33 \\
$\mathbf{9}$ & CA & 25 & 35 \\
$\mathbf{1 0}$ & CF & 31 & 35 \\
$\mathbf{1 1}$ & CR & 27 & 29 \\
$\mathbf{1 2}$ & DEL & 28 & 32 \\
$\mathbf{1 3}$ & DAS & 25 & 29 \\
$\mathbf{1 4}$ & CEL & 23 & 28 \\
$\mathbf{1 5}$ & CIL & 24 & 29 \\
$\mathbf{1 6}$ & DEF & 25 & 31 \\
$\mathbf{1 7}$ & RS & 26 & 32 \\
$\mathbf{1 8}$ & SR & 27 & 36 \\
$\mathbf{1 9}$ & YT & 28 & 32 \\
$\mathbf{2 0}$ & EY & 29 & 34 \\
\hline & Total & 535 & 648 \\
& Y & 26,75 & 32,4 \\
\hline
\end{tabular}

The Paired Samples Statistics table shows the descriptive values of each variable in the paired sample. Initial tests have a mean value of 26.75 from 20 data. The data distribution (Std. Deviation) obtained was 2,381 with a standard error of 0.532. Final Test has an average value (mean) of 32.40 from 20 data. Data distribution (Std. Deviation) obtained 2,027 with a standard error of 0.655 . This shows the final test on the data is higher than the initial test (see table 2).

Table 2. Paired Samples Statistics

\begin{tabular}{cccccc}
\hline & & Mean & N & Std. Deviation & Std. Error Mean \\
\hline Pair 1 & Pre-Test & 26.75 & 20 & 2.381 & .532 \\
& Post-Test & 32.40 & 20 & 2.927 & .655 \\
\hline
\end{tabular}

Paired Samples Correlations, table 4 shows the correlation value that shows the relationship between the two variables in the paired sample. This was obtained from the Pearson bivariate correlation coefficient (with a two-tailed significance test) for each pair of variables entered.

Table 4. Paired Samples Correlations

\begin{tabular}{ccccc}
\hline & & N & Correlation & Sig. \\
\hline Pair 1 & Pre-Test \& Post-Test & 20 & .710 & .000 \\
\hline
\end{tabular}

Paired Samples Test in table 5, is the main table of output that shows the results of the tests carried out. This can be seen from the significance value (2-tailed) in the table. The significance value (2-tailed) of this case sample was 0.000 ( $\mathrm{p}<0.05)$. So, the results of the initial test and final test underwent significant changes (meaning). 


\begin{tabular}{|c|c|c|c|c|c|c|c|c|c|}
\hline & & \multicolumn{5}{|c|}{ Paired Differences } & \multirow[t]{2}{*}{$\mathrm{t}$} & \multirow[t]{3}{*}{$\mathrm{df}$} & \multirow{3}{*}{ Sig. (2-tailed) } \\
\hline & & & $\begin{array}{l}\text { Std. } \\
\text { Deviati }\end{array}$ & $\begin{array}{l}\text { Std. } \\
\text { Error }\end{array}$ & $95 \%$ & $\begin{array}{l}\text { idence I } \\
\text { the } \\
\text { erence }\end{array}$ & & & \\
\hline & & Mean & on & Mean & Lower & Upper & & & \\
\hline Pair 1 & $\begin{array}{l}\text { Pre-test } \\
\text { Post-Test }\end{array}$ & $\begin{array}{c}- \\
5.650\end{array}$ & 2.084 & .466 & -6.626 & -4.674 & $\begin{array}{c}- \\
12.122\end{array}$ & 19 & .000 \\
\hline
\end{tabular}

Based on descriptive statistics the initial test and the final test prove the final test is higher. It can be concluded that the activity of moving to beats can improve children's self- regulation. That indicated that "moving to the beat" has positive influence on children's self-regulation.

\subsection{Discussion}

The new school year is a heavy start for early childhood teachers to implement classroom rules. Children come with various habits that are brought from their respective homes. Classroom rules are a new thing that makes children different in adapting class rules. Some children have difficulty in obeying regulations, such as lining up, waiting in line, or keeping their utensils in place, because self-regulation according to Booth et al., (2019) is an integral part of learning to wait, think, and reflect to react appropriately in certain situations. The beginning of this school is a good time to conduct research that moving to the beat activities will be able to influence children's self-regulation.

The researcher together with the teacher observes the behaviour and ability of children's self-regulation in the first few weeks of school, as a pre-test to measure children's selfregulation. Then the teacher begins to treat moving to the beat activities to stimulate the child's self-regulation aspects. Learning activities moving to the beat is certainly very interesting interests of children, because basically children love music. The teacher invites children in the morning meeting or circle time to do this activity. Children enjoy moving while holding the hula hoop jumping right and left following the music tempo (slow tempo). In the first week of the activity, there has not been any change in the selfregulation of children, some children are still unable to control themselves to create a positive classroom climate. As Diamond (2013) opinion that self-regulation here represents the ability of children to recognize, monitor and manage emotional capacity, behaviour and attention to actions directed at the goal.

The second week the activity of moving to the beat uses different properties, also uses different music. Beat music at medium tempo is made more varied, dance moves to follow music are made wider, children are asked to maintain their distance when moving, this is done to see their concentration on things that need to be consistently done. Some children are unable to maintain distance, children who are unable to maintain distance are recorded as children with low self-regulation in another daily activities. Edossa's et al., (2018) 
study show that the structure of self-regulation is multidimensional, and its aspects are interdependent in children's development.

The moving to the beat activity, which was carried out in the third week, showed the enthusiasm of the children in this activity increased. Children begin to ask what property is being used and what music is going to be rung. Children begin to choose and make agreement with another child on the property to be used and ask the teacher to play the music they like, sometimes they ask the teacher not to change the tempo of the song, but the faster the music beats, the more boisterous and happier they are. But the closing activities of the teacher always play relaxation music for children, children are asked to close their eyes until the music playing stops. This has an extraordinary effect on a child's attitude. For example, children become more patient waiting in line, because according to Baltazar et al., (2019) Music is a common resource for the regulation of emotions, moods, and stress.

In the last week of moving to the beat activities, within eight weeks, children have shown progress in their self-regulation abilities. Through the formation of dance movements, children can understand that they and take turns to play, no need to fight over. The music tempo arranges them to enter in the right movements according to the beat of the music, even the children at the end of the activity have been able to count beat in music. Sometimes they move while singing, or they move to the music, but their mouth counts beat with medium or fast tempo beats. The development of this ability affects children's attitudes in self-control, such as not easily hitting friends, lining up in an orderly manner, orderly in circle time activities, enthusiastic in activities that require patience, such as taking turn when playing swing. Comparison of paired t-test results shows the significance before and after the move to the beat activity. This research has supported the literature review conducted by Williams (2018) who argues that rhythmic movement activities hold strong promise in self-regulation of early childhood. Active music involvement in early childhood is easily implemented universally, with many teachers already using music activities as a regular part of programming. Evidence of Williams (2018) literature studies also shows that activities must be specifically designed to stimulate motor coordination and synchronization skills and instil challenging selfregulation games, and well-established relaxation techniques.

\section{CONCLUSION}

Based on the results of research can be concluded that, moving to the rhythm can affect early childhood self-regulation. So that moving according to the rhythm can improve selfregulation of early childhood. The limitation of this research is that the number of research samples is a minimum sample, so it has not represented the population, so this study cannot be generalized, only applies to samples at the research site. To improve selfregulation of early childhood can be influenced by several other factors, such as parenting, parental relationships with children, teacher relations with students, play or learning environment, and others. For this reason, further research is recommended to see the influence of other factors on early childhood self-regulation. 


\section{REFERENCES}

Baltazar, M., Västfjäll, D., Asutay, E., Koppel, L., \& Saarikallio, S. (2019). Is it me or the music? Stress reduction and the role of regulation strategies and music. Music \& Science, 2, 205920431984416. https://doi.org/10.1177/2059204319844161

Blair, C., \& Raver, C. C. (2012). Individual development and evolution: Experiential canalization of self-regulation. Developmental Psychology, 48(3), 647-657. https://doi.org/10.1037/a0026472

Blair, C., \& Raver, C. C. (2015). School Readiness and Psychobiological Approach. August 2014, 1-21. https://doi.org/10.1146/annurev-psych-010814-015221

Blair, C., \& Razza, R. P. (2007). Relating Effortful Control, Executive Function, and False Belief Understand... Child Development, 78(2), 647-663. https://doi.org/10.2307/4139250

Booth, A., O'Farrelly, C., Hennessy, E., \& Doyle, O. (2019). 'Be good, know the rules': Children's perspectives on starting school and self-regulation. Childhood, 26(4), 509-524. https://doi.org/10.1177/0907568219840397

Cadima, J., Verschueren, K., Leal, T., \& Guedes, C. (2016). Classroom Interactions, Dyadic Teacher-Child Relationships, and Self-Regulation in Socially Disadvantaged Young Children. Journal of Abnormal Child Psychology, 44(1), 7-17. https://doi.org/10.1007/s10802-015-0060-5

Charissi, V., \& Rinta, T. (2014). Children's musical and social behaviours in the context of music-making activities supported by digital tools: Examples from a pilot study in the UK. Journal of Music, Technology and Education, 7(1), XXXXX. https://doi.org/10.1386/jmte.7.1.39_1

Dalla Bella, S., Berkowska, M., \& Sowiński, J. (2015). Moving to the Beat and Singing are Linked in Humans. Frontiers in Human Neuroscience, 9(December), 1-13. https://doi.org/10.3389/fnhum.2015.00663

Danielsen, A., Haugen, M. R., \& Jensenius, A. R. (2015). Moving to the Beat: Studying Entrainment to Micro-Rhythmic Changes in Pulse by Motion Capture. 0315.

Diamond, A. (2013). Functions, Executive. Annual Reviews Psychology, 29(146), 13-15. https://doi.org/10.1146/annurev-psych-113011-143750

Diamond, A. (2016). Why improving and assessing executive functions early in life is critical. In Executive function in preschool-age children: Integrating measurement, neurodevelopment, and translational research. (pp. 11-43). American Psychological Association. https://doi.org/10.1037/14797-002

Duckworth, A. L., Quinn, P. D., \& Tsukayama, E. (2012). What No Child Left Behind Leaves Behind: The Roles of IQ and Self-Control in Predicting Standardized Achievement Test Scores and Report Card Grades. Journal Education Psycology, 104(2), 439-451. https://doi.org/10.1037/a0026280. What 
Edossa, A. K., Schroeders, U., Weinert, S., \& Artelt, C. (2018). The development of emotional and behavioral self-regulation and their effects on academic achievement in childhood. International Journal of Behavioral Development, 42(2), 192-202. https://doi.org/10.1177/0165025416687412

Eunhye, H., Cynthia, K. B., \& Jeon, L. (2015). The Association Between Teachers' ChildCentered Beliefs and Children's Academic Achievement: The Indirect Effect of Children's Behavioral Self-regulation. Developmental Psychology, 44, 309-325. https://doi.org/DOI 10.1007/s10566-014-9283-9

Flook, L., Smalley, S. L., Kitil, M. J., Galla, B. M., Kaiser-Greenland, S., Locke, J., Ishijima, E., \& Kasari, C. (2010). Effects of mindful awareness practices on executive functions in elementary school children. Journal of Applied School Psychology, 26(1), 70-95. https://doi.org/10.1080/15377900903379125

Fujii, S., \& Schlaug, G. (2013). The Harvard Beat Assessment Test (H-BAT): A battery for assessing beat perception and production and their dissociation. Frontiers in Human Neuroscience, $\quad$ 7(November), 1-16. https://doi.org/10.3389/fnhum.2013.00771

Gammage, P. (2019). Early childhood education and care in context. In Early Years Education and Care. https://doi.org/10.4324/9781315768700-2

George, E. M., \& Coch, D. (2011). Music training and working memory: An ERP study. Neuropsychologia, 49(5), 1083-1094. https://doi.org/10.1016/j.neuropsychologia.2011.02.001

Hallam, S. (2010). The power of music: Its impact on the intellectual, social, and personal development of children and young people. https://doi.org/10.1177/0255761410370658

Howes, C., Burchinal, M., Pianta, R., Bryant, D., Early, D., Clifford, R., \& Barbarin, O. (2008). Ready to learn? Children's pre-academic achievement in preKindergarten programs. Early Childhood Research Quarterly, 23(1), 27-50. https://doi.org/10.1016/j.ecresq.2007.05.002

Jacobson-Chernoff, J., Flanagan, K. D., McPhee, C., \& Park, J. (2007). Preschool: First findings from the preschool follow-up of the Early Childhood Longitudinal Study, Birth Cohort (ECLS-B). In National Center for Education Statistics. NCES Publication No. 2008-025.

Lobo, Y. B., \& Winsler, A. (2006). The effects of a creative dance and movement program on the social competence of head start preschoolers. Social Development, 15(3), 501-519. https://doi.org/10.1111/j.1467-9507.2006.00353.x

Marsden, E., \& Torgerson, C. J. (2012). Article in Oxford Review of Education ·. May 2016. https://doi.org/10.2307/41702779

McClelland, M. M., \& Cameron, C. E. (2012). Self-Regulation Early Childhood: Improving Conceptual Clarity and Developing Ecologically Valid Measures. 
Child Development Perspectives, 6(2), 136-142. https://doi.org/10.1111/j.17508606.2011.00191.x

OCDE. (2013). Education at a Glance 2013. https://doi.org/10.1787/gov_glance-2011en

Pianta, R., Howes, C., Burchinal, M., Bryant, D., Clifford, R., Early, D., \& Barbarin, O. (2005). Features of Pre-Kindergarten Programs, Classrooms, and Teachers: Do They Predict Observed Classroom Quality and Child-Teacher Interactions? Applied Developmental Science, 9(3), 144-159. https://doi.org/10.1207/s1532480xads0903_2

Ponitz, C. C., McClelland, M. M., Matthews, J. S., \& Morrison, F. J. (2009). A Structured Observation of Behavioral Self-Regulation and Its Contribution to Kindergarten Outcomes. Developmental Psychology, 45(3), 605-619. https://doi.org/10.1037/a0015365

Putkinen, V., Tervaniemi, M., \& Huotilainen, M. (2013). Informal musical activities are linked to auditory discrimination and attention in 2-3-year-old children: An eventrelated potential study. European Journal of Neuroscience, 37(4), 654-661. https://doi.org/10.1111/ejn.12049

Putkinen, V., Tervaniemi, M., Saarikivi, K., \& Huotilainen, M. (2015). Promises of formal and informal musical activities in advancing neurocognitive development throughout childhood. Annals of the New York Academy of Sciences, 1337(1), 153-162. https://doi.org/10.1111/nyas.12656

Salisch, M. Von, Haenel, M., \& Denham, S. A. (2015). Early Education and Development Self-Regulation, Language Skills, and Emotion Knowledge in Young Children From Northern Germany. July 2015. https://doi.org/10.1080/10409289.2015.994465

Schibli, K., Van Roon, P., MacDougall, K., \& D’Angiulli, A. (2015). Practicing selfregulation through music: An ERP study comparing child musicians and nonmusicians. International Journal of Developmental Neuroscience, 47(2015), 97. https://doi.org/10.1016/j.ijdevneu.2015.04.265

Thomason, A. C., \& La Paro, K. M. (2009). Measuring the Quality of Teacher-Child Interactions in Toddler Child Care. Early Education and Development, 20(2), 285-304. https://doi.org/10.1080/10409280902773351

Varela, W., \& Abrami, P. C. (2014). Self-regulation and music learning: A systematic review. https://doi.org/10.1177/0305735614554639

Wiebe, S. A., Espy, K. A., \& Charak, D. (2008). Using Confirmatory Factor Analysis to Understand Executive Control in Preschool Children: I. Latent Structure. Developmental Psychology, 44(2), 575-587. https://doi.org/10.1037/00121649.44.2.575 
Williams, K. E. (2018). Moving to the Beat: Using Music, Rhythm, and Movement to Enhance Self-Regulation in Early Childhood Classrooms. International Journal of Early Childhood, 50(1), 85-100. https://doi.org/10.1007/s13158-018-0215-y

Williams, K. E., Barrett, M. S., Welch, G. F., Abad, V., \& Broughton, M. (2015a). Associations between early shared music activities in the home and later child outcomes: Findings from the Longitudinal Study of Australian Children. Early Childhood Research Quarterly, 31, 113-124. https://doi.org/10.1016/j.ecresq.2015.01.004

Williams, K. E., Barrett, M. S., Welch, G. F., Abad, V., \& Broughton, M. (2015b). Associations between early shared music activities in the home and later child outcomes: Findings from the Longitudinal Study of Australian Children. Early Childhood Research Quarterly, 31, 113-124. https://doi.org/10.1016/j.ecresq.2015.01.004

Williams, K. E., \& Berthelsen, D. (2019). Implementation of a rhythm and movement intervention to support self-regulation skills of preschool-aged children in disadvantaged communities. Psychology of Music, 47(6), 800-820. https://doi.org/10.1177/0305735619861433

Williford, A. P., Whittaker, J. E. V., Virginia, E., Downer, J. T., Williford, A. P., Whittaker, J. E. V., \& Vitiello, V. E. (2013). Early Education and Development Children's Engagement Within the Preschool Classroom and Their Development of Self-Regulation Children 's Engagement Within the Preschool Classroom and Their Development of Self-Regulation. Early Education and Development, 24, 162-187. https://doi.org/10.1080/10409289.2011.628270

Zachariou, A., \& Whitebread, D. (2016). Musical play and self-regulation: Does musical play allow for the emergence of self-regulatory behaviours? 4937(February). https://doi.org/10.1080/21594937.2015.1060572

Zimmerman, B. J. (2010). Self-Regulated Learning and Academic Achievement: An Overview. Educational Psychologist, 25(1), 3-17. https://doi.org/10.1207/s15326985ep2501 